UAM Vol. 40/2 Poznań 2013

\title{
ARTÍCULOS
}

\author{
ALFONS GREGORI
}

Universidad Adam Mickiewicz de Poznań

alfons@amu.edu.pl

\section{LAS CORRIENTES DE INVESTIGACIÓN EN TEORÍA DE LO FANTÁSTICO PRESENTES EN EL HISPANISMO: ESTADO DE LA CUESTIÓN}

\begin{abstract}
Alfons Gregori, Las corrientes de investigación en teoría de lo fantástico presentes en el hispanismo: estado de la cuestión [Trends of research on fantastic theory in Hispanic studies: state of the investigation], Studia Romanica Posnaniensia, Adam Mickiewicz University Press, Poznań, vol. XL/2: 2013, pp. 5-23. ISBN 978-83-232-2597-3. ISSN 0137-2475. eISSN 2084-4158.
\end{abstract}

Tzvetan Todorov typified the literary fantastic as an autonomous gender in 1970, separating it from marvelous texts and other bordering modes that contained unreal or supernatural elements. In the Latin-American Hispanic studies his model and several other views about fantastic literature encouraged an advancing body of important theorizing, more or less critic with his definition of the gender, finding or not correlations with French or Anglo-Saxon alternative approaches to Todorov's taxonomist view. In Spain a consistent incorporation to the debate occurred much later thanks to Catalan researcher David Roas. In the present article it is presented a brief state of the investigation about the literary fantastic through the last 20 years in Hispanic studies, when the first reactions to structuralist visions of the subject were enriched by sociocritical, historic, psychologist and philological contributions. Two particular, solid but conflicting approaches are analyzed as the opposed poles of a quite wide spectrum of different understandings and ways of doing literary fantastic: on one hand, Mexican scholar Ana María Morales philologist and intratextual-based view, and, on the other hand, Roas psychologist and actual-reader-response-based position. This accurately examined presentation shows the complex variety and the enormous interest of Hispanic studies theorizing about fantasy worlds.

Keywords: fantasy, literary fantastic, marvelous literature, Spanish literary criticism, literary theory

\section{INTRODUCCIÓN}

Lo fantástico ha sido históricamente un cajón de sastre en que se ha colocado la más variopinta tipología de textos literarios. De hecho, su sistematización más sólida - asumida mayoritariamente como fundacional - se dio hace unas pocas décadas de la mano de Tzvetan Todorov con su estudio Introduction à la littérature fantastique. Muchas han sido las críticas que ha recibido, tomándole como punto de referencia de un estructuralismo que no fue capaz de ir más allá de sus límites, pero también han 
sido abundantes los actos de asunción de sus postulados básicos —especialmente su construcción taxonómica de los subgéneros vinculados a lo fantástico-, que le han convertido en el puntal teórico para trabajos cuyas perspectivas de análisis difícilmente compartiría el maestro búlgaro naturalizado francés.

Por otro lado, dentro del mundo del hispanismo destaca la cuestión de la pronunciada asimetría entre el espacio peninsular y el ámbito hispanoamericano. En efecto, si bien ambos compartirían manifestaciones literarias del fantástico clásico que conducen al (o conviven con el) llamado neofantástico, en el último de los ámbitos mencionados se acontecen otras destacadas emergencias de lo fantástico, fenómenos categorizados diversamente como realismo mágico, real maravilloso o realismo fantástico ${ }^{1}$. El objetivo del presente artículo es ofrecer unas pautas para conocer qué teorías sobre ese primer campo de acción creativa, que se aparta conceptualmente y estéticamente de las obras de Carpentier, García Márquez y demás ${ }^{2}$, han gozado de más impacto en los estudios sobre el tema elaborados en el seno del hispanismo ${ }^{3}$ en los últimos 20 años, así como perfilar de qué modo han podido afectar esa realidad asimétrica y esa singularidad hispanoamericana en el posicionamiento de los investigadores acerca de diversas controversias recurrentes en el mundo de los estudios sobre lo fantástico literario. En este sentido, no vamos a introducir las disquisiciones habidas sobre textos concretos o sobre la estética de autores individuales, aunque obviamente todos ellos van a servir para ilustrar y ejemplificar las diversas perspectivas teóricas alrededor de lo fantástico en general.

\section{LO FANTÁSTICO EN EL MUNDO DE LOS ESTUDIOS HISPÁNICOS}

De entre las monografías recientes en lengua castellana sobre lo fantástico literario, destacan en número las elaboradas por estudiosos hispanoamericanos. El investigador cubano José Miguel Sardiñas sacó a la luz en 2007 un reader de la teoría del

${ }^{1}$ Para un análisis detallado y altamente informativo sobre las diversas concepciones que se han prodigado acerca de dichas categorizaciones literarias, v. Llarena (1997).

${ }^{2}$ Con todo, resulta trabajoso obviar completamente trabajos que integran en lo fantástico estas vertientes hispanoamericanas, como el artículo de Oscar Hahn (1998), que trata de acercar al lector español la trayectoria del cuento fantástico hispanoamericano en el contexto de las modalidades fronterizas de lo real maravilloso y el realismo mágico.

${ }^{3}$ Por lo que respecta a la comprensión y aplicación de este término en el presente trabajo, el factor determinante para la inclusión de aproximaciones teóricas en el mismo ha sido su lengua de publicación, eso es el español, así como el campo de estudio de sus autores, que parcial o completamente abarca manifestaciones de la literatura española e iberoamericana. Cabe realizar esta aclaración porque los referentes decimonónicos o anteriores que aparecen en las mencionadas aproximaciones raramente pertenecen al ámbito de creación en castellano (a no ser que sean trabajos de investigación historiográfica, además de teóricos, como Roas [2006a, 2011a]), y tampoco suelen pertenecer a él la mayoría de los que analizan el panorama de lo fantástico previo a la Segunda Guerra Mundial. Por razones de distancia teórica y dificultades a la hora de hacer encajar en el conjunto problemáticas internas diversas, no van a ser tratados análisis específicos de las literaturas no castellanas presentes en el Estado español, algo que podría constituir un trabajo a posteriori centrado en la Península ibérica. 
pensamiento producido en esa gran región del planeta sobre esta modalidad literaria ${ }^{4}$, que ha sido definido por el crítico mexicano Francisco Aragón como una confirmación de la importancia de dicho pensamiento a nivel global en el mundo de los estudios literarios: "[...] sin duda resulta extraordinario poder afirmar que parte de las teorías más importantes sobre lo fantástico en el mundo hayan sido escritas por nuestros pensadores" (Aragón, 2008: 249). Sardiñas (2006) presenta de manera escueta pero efectiva las tres etapas que, a su parecer, estructuran la teorización sobre lo fantástico en Hispano-américa: en la década de los 40 del s. XX, con Borges y Bioy Casares de protagonistas de discursos personales sobre la cuestión; en los años 50 y 60, con los primeros estudios en la dirección de unas primeras argumentaciones teóricas, en que encontramos a Ana María Barrenechea o a Enrique Anderson Imbert; y, finalmente, la época postodoroviana, que "es el lapso más rico y variado, en que ven la luz los estudios más rigurosos, también académicos, y en que se produce un intercambio más activo y polémico con las teorías europeas y norteamericanas"5 (Sardiñas, 2006: 91). Como menciona el mismo Sardiñas (2006: 91) en sus conclusiones, no hay que ser un lince para observar una elevada presencia de argentinos en la nómina de teóricos, también en esta última etapa de su división: Rosalba Campra, Jaime Alazraki, Susana Reisz y Pampa O. Arán.

La primera de ellas, Rosalba Campra ${ }^{6}$ es autora de un volumen completo sobre el tema que aquí se aborda, Territorios de la ficción: lo fantástico ${ }^{7}$ (2006). Transponiendo

${ }^{4}$ Desgraciadamente, no he podido consultar este volumen por falta de disponibilidad. Por ello, voy a utilizar un artículo del investigador cubano que se publicó el año anterior en la revista de la Universidad Veracruzana Semiosis, artículo que según afirma él mismo es una síntesis parcial de su estudio en el reader (Sardiñas, 2006: 77).

${ }^{5}$ Descubrimos trabajos que abarcan gran variedad de metodologías y perspectivas, hasta la deconstrucción más punzante, como el artículo de la norteamericana Susan Antebi (2007) sobre los ajolotes y su relación con lo fantástico, el cual, curiosamente, muestra que el tema recurrente del gran cuento de Cortázar no está ni mucho menos agotado (y en este sentido lo menciono, a pesar de tratar una obra muy concreta). Por otro lado, y en el mismo volumen de artículos, el tratamiento del concepto de lo maravilloso dentro de modalidades literarias colindantes con lo fantástico que leemos en estudios como los de la portuguesa Maria Eugénia Pereira (2007) muestra que todavía queda mucho camino por hacer en este sentido. Desde otro orden de cosas, Julio Prieto analiza en diversos de sus trabajos las transferencias y contactos entre las vanguardias y lo fantástico en el marco rioplatense, como por ejemplo en un estudio de 2007 sobre Borges y Macedonio Fernández, aquí con el catalizador de la metafísica.

${ }^{6}$ Habiendo ejercido la docencia y la investigación en La Sapienza de Roma desde muchos años, Campra ha convivido y dialogado de tal manera con los teóricos de la literatura italianos (cf. Arán, 2004: 8-9) que, en buena medida se la puede considerar una hispanista italianizada que aporta al hispanismo internacional su amplia experiencia en lo fantástico visto desde las instancias de Italia.

${ }^{7}$ En realidad este texto en español parece ser que es la versión original de la obra publicada en italiano bajo el título homónimo Territori della finzione: Il fantástico nella literatura (2000) (v. Campra, 2001: 153), que a su vez es una refundición completada de diversos trabajos en forma de artículos que la autora había publicado entre 1981 y 1991. 
terminología del mundo de la lingüística, de acuerdo con un modelo que evoca lo estructuralista, la autora señala que los niveles sintácticos y discursivos ${ }^{8}$ del relato fantástico — además del nivel semántico "tradicional"— también padecen transgresiones que suponen un choque de órdenes irreconciliables, con el resultado de una subversión absoluta del concepto de realidad por el "escándalo racional" que supone que ambos órdenes en conflicto coincidan en el espacio narrativo", sin la sumisión del uno al otro (Campra, 2008: 26-27). En el fondo, la reflexión de Campra (2008: 189-190) abarca también la naturaleza misma de lo literario en diversos periodos de la Historia: “[...] lo fantástico no es sólo un hecho de percepción del mundo representado, sino también una interacción entre un fenómeno de escritura y una estrategia de lectura"10. Justamente esta concepción del texto fantástico fue debidamente evaluada y pormenorizada en el trabajo de la israelí Mery Erdan Jordan (1998), que analiza la evolución del género literario en relación con las concepciones del lenguaje, especificando que hay diferencias en ese sentido entre el fantástico romántico, el clásico de fondo realista y el posmoderno, que a su vez también presenta distintas vertientes vinculadas al fenómeno del lenguaje que podemos percibir en ellos.

Dentro del ámbito de formación argentino, Pampa O. Arán, cordobesa igual que Rosalba Campra, ha escrito otra de las monografía recientes en español que tratan en su conjunto sobre la teoría de la literatura fantástica: El fantástico literario: Aportes teóricos (1999). Como reconocimiento a su labor crítica, Arán (cf. 1999: 64-88) presenta los principios teóricos de Todorov bajo el ojo crítico de dos investigadoras argentinas que, como afirma esta autora, lo matizan, corrigen y profundizan. Se trata de la misma Campra y Ana Barrenechea. Ahora bien, en el trabajo de Arán, además de la productiva aplicación de los planteamientos bajtinianos, destaca principalmente la introducción de una productiva y sugerente distinción entre dos vertientes del término fantástico. En concreto, por un lado, lo imaginario como fenómeno antropológico $\mathrm{y}$, por el otro, un discurso de mundo posible con propiedades contradictorias y ambiguas que se limitan a lo intratextual, expresando tal distinción principalmente a partir del uso de dos marcas morfológicas diferentes, en forma de artículos:

${ }^{8}$ El nivel sintáctico se refiere básicamente a la concatenación lógico-causal de la episteme occidental, mientras que el nivel discursivo se traduce en la violación transgresora que se produce a través de la modalidad de lo fantástico afirmado a partir de la segunda mitad del s. XX, al haberse desgastado los motivos semánticos como la figura del vampiro o el fantasma (v. Campra, 2008: 189).

9 Partiendo de postulados constructivistas, Prada Oropeza (2006: 64) sigue tanto este conclusión de Campra como la debilidad de esta por el vocabulario de la lingüística, remarcando que "[...] la tensión semántica a que nos obliga la narración fantástica no descalifica a uno de sus elementos por «absurdo», «irreal» o «falso»", dando lugar al espacio fantástico verosímil.

${ }^{10}$ En su estudio Los poderes de la ficción (1993), el venezolano Víctor Bravo amplia también el horizonte de lo fantástico a través de una bien trabada concatenación de análisis sobre las modalidades literarias colindantes, o desgranando los aspectos que lo integran, a partir de las ideas-fuerza transhistóricas de la Alteridad y la Identidad en la literatura. 
Se hace entonces necesario distinguir entre lo fantástico como categoría epistemológica que puede alimentar diferentes géneros en otros discursos sociales (creencias religiosas, fenómenos de ocultismo, magia, folklore, etc.), y el fantástico que remite en clave literaria a la oposición con el realismo y que ha servido para caracterizar de manera imprecisa una vasta producción literaria cuyo régimen de verosímil es diferente (Arán, 1999: 12).

En efecto, cierto es que un buen número de teóricos de lo fantástico se ha centrado en el análisis textualista basado en supuestas características propias de los textos literarios, en un (post)estructuralismo revelado como extensión del formalismo ruso que, con sus postulados, se afanó en independizar la teoría literaria como disciplina literaria. Esto se produjo especialmente después de algunas muestras de cariz tematológico de investigadores (Penzoldt, Caillois, Vax) que se dedicaron a investigar los motivos sobrenaturales recurrentes en los textos artísticos, muchos de ellos localizables igualmente en el imaginario popular o en la tradición folklórica. Con todo, quizás la obra que compila y analiza con mayor agudeza diferentes aspectos que podemos agrupar bajo el concepto de "lo fantástico" es Le miroir de sorcière (1992), del estudioso francés Jean Fabre, que trabaja bajo los principios de la sociocrítica (aunque teñida de mitocrítica). Paralelamente, y en total contraste, no podemos olvidar a diversos autores católicos anglosajones, entre los que destacan J.R.R. Tolkien o C.S. Lewis, que tratarían lo fantástico de Arán en un sentido transcendente, más allá del análisis meramente inmanentista de los investigadores mencionados, dibujando una esencia de lo irreal que moralmente supera lo real y escatológicamente señala un camino de adoctrinada salvación ${ }^{11}$.

\section{LO FANTÁSTICO COMO REFLEXIÓN TEÓRICA EN DOS AUTORES HISPÁNICOS}

En las siguientes líneas van a ser presentadas dos posturas críticas antagónicas que ayudarán a perfilar los márgenes de distintas maneras de percibir y analizar la literatura fantástica, encarnados en dos investigadores muy relevantes de la materia, además de dos continentes diferentes: la americana Ana María Morales, profesora de la Universidad Nacional Autónoma de México, y David Roas, docente de la Universitat Autònoma de Barcelona. Sus puntos de vista y su práctica metodológica nos situarán de pleno en el debate sobre el papel de lo extratextual en la definición de la categoría de lo fantástico, que en el caso de Morales es tendiente a ser nula, mientras que en el caso de Roas resulta del todo prevalente ${ }^{12}$.

${ }^{11}$ Como señala Jackson (1981: 2) en referencia a estos escritores: "Literature of the fantastic has been claimed as 'transcending' reality, 'escaping' the human condition and constructing superior alternate, 'secondary' worlds".

12 Francisco Aragón, docente de la UNAM y compañero por tanto de Morales, parece querer tirar leña al fuego respecto a las disputas conceptuales entre Roas y Morales, al hacer comparaciones entre el reader del profesor catalán y el de Sardiñas, señalando que el texto de Susana Reisz editado 


\subsection{LA POSICIÓN INTRATEXTUAL DE ANA MARÍA MORALES}

Morales constituye quizás el caso más sintomático en que se conjuga la tarea de teorización literaria y la acción dinamizadora de los estudios sobre lo fantástico. En efecto, Morales ha sido desde sus inicios el alma de los Coloquios Internacionales de Literatura Fantástica ${ }^{13}$, que se iniciaron en 1999 en La Habana y han tenido hasta la fecha nueve ediciones, con la décima prevista en Lausana (Suiza) para junio de 2013. En ellos han intervenido los más importantes especialistas de lo fantástico del mundo hispanoamericano, intentando además alternar las sedes en Europa y América. De los volúmenes que recogían artículos presentados en dichos coloquios como comunicaciones, ya sea en forma de monografía o de dosieres en revistas académicas, ha surgido el grueso de textos para el conocimiento y el debate acerca de lo fantástico en el mundo hispanohablante. En este sentido, su labor organizativa - en colaboración con otros responsables académicos- ha resultado crucial.

Con todo, en estas líneas nos interesa tratar la vertiente investigadora de Morales. $\mathrm{Su}$ trabajo se fundamenta en postulados narratológicos a caballo del estructuralismo ${ }^{14}$ y de la teoría de la recepción, en especial el punto de partida de la concepción todoroviana, que se afana a clasificar para entender mejor, la figura literaria del implizite Leser de Iser, y en un elevado dominio de la constitución y desarrollo de los géneros literarios, especialmente los medievales. Así, Morales se aleja lo suficiente de las acotaciones teóricas de Todorov, sin privarse además de criticarlos explícitamente ${ }^{15}$, pero se mantiene fiel a los principios de lo intratextual como único objeto de estudio posible en los confines de la seriedad académica ${ }^{16}$. La siguiente cita lo explicita soberanamente:

Así, lo fantástico sólo puede surgir dentro de una obra en la que se ha codificado la realidad intratextual como realista o mimética y hace su aparición un fenómeno que puede ser percibido (siempre por una instancia intratextual) como una manifestación que viola las leyes sobre las que se asienta el presupuesto de realidad de ese mundo textual (Morales, 2004: 27).

Todorov (1970: 39-40) ya se burlaba de las aproximaciones pragmático-historicistas dependientes de la reacción del lector real o de la interpretación crítica contextual, aseverando que no se podía juzgar la categoría genérica de un texto a partir de la

por Roas resulta bastante menos comprensible que la versión que aparece en el volumen a cargo de Sardiñas, por no estar completo, y añade que la versión del artículo de Campra (traducido por Sardiñas) abarca menos aspectos y es menos claro en la compilación del docente de la UAB (Aragón, 2008: 253).

${ }^{13}$ En ello ha contado con la colaboración habitual de José Miguel Sardiñas y Marco Kunz.

${ }^{14}$ Comprobamos la empática ironía de la autora mexicana cuando aporta argumentos que, como ella misma explicita, tienen un "[...] tufillo envejecido a estructuralismo" (Morales, 2004: 36).

15 Algunas de las observaciones de Morales han sido habituales en la revisión crítica del legado todoroviano: la inestabilidad de su modelo hesitativo y la escasez de corpus resultante (Morales, 2000a: 27).

${ }^{16}$ Así, en un par de sus trabajos define elogiosamente al crítico de origen búlgaro como "[...] gran hito, verdadero parteaguas en los estudios de lo fantástico [...]" (Morales, 2000a: 26; cf. 2004: 25). 
"sangre fría" de los lectores ${ }^{17}$. Con diferentes palabras, la misma idea la hallamos en Morales (2004: 29): “[...] no puede ser el [argumento] de un discurso teórico que permita por este camino la clasificación de los textos en «A»o «B», en dependencia de la mayor o menor incredulidad que un sujeto tenga o entienda en un momento dado". Este acercamiento es compartido por otros estudiosos, como el investigador argentino Daniel Altamiranda (2000: 73), que focaliza en lo que denomina "[...] perspectivismo propio de la voz narrativa seleccionada" y en la propiedad del texto de contener explicaciones alternativas y mutuamente excluyentes como claves en el efecto de incertidumbre que caracterizaría lo fantástico ${ }^{18}$.

Por otro lado, en "Teoría y práctica de lo fantástico. Modelos y rupturas" (2000) lleva a cabo una síntesis orientativa de las aproximaciones teóricas alrededor de lo fantástico desde Charles Nodier hasta Barrenechea, pasando por Roger Caillois o Louis Vax, integrando además el posicionamiento de autores hispanoamericanos que cultivaron la literatura fantástica, en especial Jorge Luis Borges, inclusión que explica como sigue: "En Latinoamérica, como en Francia un siglo antes, la especulación de lo fantástico la inician grandes escritores y sus reflexiones deben mencionarse teniendo en cuenta que hay ocasiones en que más que esbozar teorías, los autores están hablando de estéticas personales y de poéticas explícitas de sus propias obras"19 (Morales, 2000a: 27). En este sentido, Morales aprovecha su análisis del pensamiento de Julio Cortázar sobre lo fantástico para cargar contra uno de sus destacados caballos de batalla: la inadecuada identificación entre la literatura fantástica y lo terrorífico. Al entender de la autora, se trataría de un reduccionismo de lo fantástico a la literatura de terror en el que no sólo habría caído el escritor argentino, sino que se trataría de una tendencia que se constata especialmente en la

${ }^{17}$ La investigadora argentina afincada en Suecia Andrea Castro (2002: 35) desmantela la elaboración todoroviana de un lector implícito en su libro seminal, mostrando el mal uso del concepto de "incertidumbre" que Todorov aplica al supuesto lector intratextual: "[...] a los fines de que quede claro que la reacción en el lector es respuesta a estrategias textuales, preferiremos hablar de ambigüedad. La ambigüedad se encontrará en el texto mismo, mientras que la incertidumbre nos obliga a personificar al lector implícito en cuanto que está constituida por un efecto que el texto provoca en el lector. [...] Afirmar que el lector implícito siente incertidumbre, es equivalente a afirmar que una estrategia textual siente incertidumbre".

${ }^{18}$ Sin embargo, el artículo de Altamiranda (2000: 62) donde desarrolla su argumentación contiene algún punto de escasa coherencia. Así, con el (supuesto) objetivo convencer al lector de la bondad de los planteamientos de cariz intratextual que presenta en su artículo sobre la literatura fantástica, cita a Di Girolamo para confirmar que "[...] el recurso a la ficcionalidad como rasgo definitorio de la literatura ha sido definitivamente descartado", expresando de este modo una de las ideas clave con que el pragmatismo radical ha querido anular cualquier veleidad de caracterización intratextual de lo literario.

19 En el ámbito peninsular contemporáneo, cabe mencionar la implicación teorizadora de uno de los autores más notables de literatura fantástica en español, el leonés José María Merino (2009: 60-62), que precisa con meridiana claridad incisiva la influencia de la Iglesia católica en la creación y recepción en España de obras centradas en lo irracional y lo sobrenatural, entre ellas de lo fantástico literario. 
crítica anglosajona, con una destacada influencia de la obra de Lovecraft Supernatural Horror in Literature (Morales, 2000a: 29).

Morales (2000a: 31-32) sitúa a Barrenechea ${ }^{20}$ como probablemente la más importante estudiosa de lo fantástico en América Latina, destacando su inmersión en el mundo teórico europeo de los 70, que le permitía estar al corriente de las novedades del estructuralismo y post-estructuralismo francés y replicar así las propuestas de Todorov a través de una formulación de lo fantástico más abierta. Va a ser Barrenechea quien, desde este posicionamiento conscientemente crítico de la teorización todoroviana, va a abrir una brecha a favor de los condicionamientos socioculturales (Morales, 2000a: 32), que son la base de ese pensamiento anglosajón acerca de lo fantástico. Obviamente, los planteamientos de Barrenechea, que se fundamentan en una oposición literaria de códigos entre lo considerado normal y anormal, no convencen a una Morales más centrada en lo intratextual que en las categorías historicistas hacia los que se deriva la obra de la crítica argentina. De hecho, en la parte final de este artículo de síntesis, su autora se exclama de tal manera que muestra nítido su posicionamiento:

Ahora bien: ¿sería demasiado arriesgado pedir que regresemos esos mismos elementos [la duda, el misterio y el desenlace abierto] al texto y no se los dejemos al lector? Si un relato presupone dos códigos diferentes de realidad y éstos entran en conflicto necesariamente hay indicios textuales que reflejan esa posición (Morales, 2000a: 35).

El postulado de tal planteamiento no es otro que el desapego de base aristotélica hacia lo anecdótico o circunstancial ("[...] lecturas momentáneas [...]") y un "[...] enfoque contextualizado [...]" dependiente sin fisuras de lo textual (Morales, 2000a: 35). Este, quizás, es el reto del planteamiento en sí. Así, en otro trabajo de Morales, "Transgresiones y legalidades (Lo fantástico en el umbral)", aclaramos el nexo que se establece entre ese mundo ficcionalizado y una realidad exterior dada: "[...] Ese mundo intratextual se presenta no sólo como verosímil, sino también como creíble y posi$\mathrm{ble}^{21}$, es que le asignamos un sistema de leyes de funcionamiento de realidad estable y conocido, paralelo al que pudiera aplicarse a la realidad extratextual" (2004: 30, cf. 2008: xii). Algunas de las preguntas que podrían surgir en este momento son: ¿Cuál sería el procedimiento que permitiría elaborar el paralelismo que plantea Morales sin tomar como prevalente o primordial el modelo de la realidad exterior? ¿Hay diferencias ontológicas que redunden en la distinción entre modelos más allá de un formalismo académico que pretenda — legítimamente - aislarse de elementos que en principio

${ }^{20}$ Esta escritora e investigadora, fallecida recientemente, fue la primera mujer que presidió la Asociación Internacional de Hispanistas a finales de los 70. En paralelo a sus estudios sobre lo fantástico, destacó su labor como lingüista, llegando a ejercer como académica correspondiente hispanoamericana de la Real Academia de la Lengua.

${ }^{21}$ La idea de verosimilitud que aparece en estas líneas debe de referirse a la idea aristotélica de la misma que se extrae del tan citado fragmento de la Poética en que el filósofo griego afirmaba que, a la hora de crear textos artísticos en el marco de la poiesis, hay que preferir lo que parece imposible a aquello que sería posible pero increíble al mismo tiempo (1998: 365 [1460a]). 
no son su objeto de estudio, aunque deba recurrir a ellos en última instancia ${ }^{22}$ ¿No sucede que, en resumidas cuentas, lo extratextual se acaba imponiendo? No son éstas preguntas retóricas, sino puntos habría que tratar con mucha más atención y argumentación cuando nos encaramos con la teoría de lo fantástico.

Por otro lado, resultan altamente interesantes y constructivas las divergencias que plantea la autor mexicana entre lo fantástico y otros géneros o modalidades literarias. Morales (2004: 26) define lo fantástico como [...] "una manera determinada de articular la ficción [...]", es decir, como "[...] un sistema narrativo específico y una categoría descriptiva especial [...]”. Su conceptualización de lo fantástico, pues, es bastante amplia y va más allá de las etiquetas de género o de subgénero que se le ha pretendido otorgar, siendo más bien un tipo de discurso de una cierta transhistoricidad que "[...] recorre distintos géneros, épocas, tradiciones e incluso distintas hibridaciones" (Morales, 2008: xiv). Ahora bien, a la hora de diferenciarlo de lo maravilloso, la autora no transita caminos ya trillados — Todorov (1970) o Jackson (1981) —, sino que, al describir la función de lo sobrenatural en los mundos ficcionales que ambos configuran, opta por atribuir a lo fantástico la idea de transgresión particular, de alusión concreta, de anómala negatividad, mientras que lo maravilloso se relaciona con la idea de aportación a la completitud, de acumulación referencial y de positividad en aras de la completitud (Morales, 2004: 32-33). En este sentido, rompe con la visión dicotómica tradicional de un maravilloso como un espacio ficcional donde solo dominaría el modo sobrenatural, y un fantástico en que lo sobrenatural se distingue en negativo de un realismo ficcional de fondo, para ahondar en un perspectiva basada en la orientación del texto y no marcar así fronteras que la práctica literaria se encarga de desarmar.

La conclusión de la estudiosa es que lo maravilloso debería constituir el marco superior dentro del cual lo fantástico — entendido de esa manera - no supondría sino una subcategoría: "[...] en mi planteamiento concibo lo fantástico como una modalidad específica dentro de un modo discursivo más general que es lo maravilloso"23 (Morales, 2008: vii). ¿Y qué sería, entonces, lo maravilloso? La investigadora mexicana lo sintetiza como sigue: "[...] un conglomerado de maneras de expresar en literatura los distintos registros de la irrealidad y lo posible, una unidad mayor" (Morales, 2008: xvii).

22 En la siguiente cita de Morales observamos un aspecto que suele ser recurrente en los textos teóricos de cariz textualista, a saber la suposición de que a partir de un texto se puede reconstruir una cultura aisladamente de aspectos externos a él, cuando los mismos espacios de indeterminación de Iser - que la estudiosa trae a colación en diversas ocasiones - no siempre son absolutamente deducibles de lo expresado en la obra o en otras obras haciendo uso de la intertextualidad: "[los textos basados en elementos fantásticos] representan su propio paradigma mediante convenciones genéricas y epocales que pueden reconstruirse dentro de los propios textos [...]" (Morales, 2008: xiii).

${ }^{23}$ En esta ocasión observamos una evolución en el pensamiento teórico de Morales, ya que algunos años antes dejó escrito lo siguiente: “[...] el verdadero tronco del que se desprenden lo feérico y fantástico no es lo maravilloso, sino que lo feérico es una categoría de lo maravilloso y éste, junto con lo fantástico pertenecen a estéticas de lo irreal" (Morales, 2000b: 50). 
De este modo, lo maravilloso abarcaría muchas de aquellas manifestaciones literarias que la crítica ha intentado etiquetar de forma diferenciada o incluso contrapuesta, siendo lo fantástico un fenómeno moderno, delimitado por unas fronteras que lo mantiene subordinado a un globalidad mucho más difuminada. Este maravilloso de Morales quizás pueda vincularse -o incluso identificarse - con el concepto de fantasy $^{24}$ que presenta Kathryn Hume (1984), un motor de creación literaria en paralelo y combinación a lo mimético.

Claro está que cabe contextualizar la cuestión: a parte de trabajos dedicados a la teoría de lo fantástico o a la literatura fantástica mexicana, Morales ha destacado sobre todo por su faceta investigadora de lo maravilloso, en especial en su vertiente medie$\mathrm{val}^{25}$ (lo maravilloso feérico ${ }^{26}$, mágico, milagroso, etc.). El panorama de la literatura a que la predispone un amplio conocimiento de la tradición textual antigua y medieval resulta bastante más extenso y rico que el de muchos de sus colegas dedicados a la teoría literaria de lo fantástico, cosa que le garantiza una menor trascendencia de un tipo de discurso que históricamente ha gozado de menos presencia y que tan sólo en los últimos siglos ha cogido un impulso destacable. De hecho, en uno de sus artículos más interesantes, "Credibilidad, percepción y reacción: Los vaivenes de lo maravilloso a lo fantástico", detalla y analiza casos en que lo fantástico en nuestra comprensión moderna se había colado en textos medievales, es decir, absteniéndose de tratar las posibles reacciones de lectores de carne y hueso que nunca conocimos ni seguramente conoceremos, Morales perfila brechas de sinrazón inquietante o incluso terrorífica ${ }^{27}$

${ }^{24}$ En este caso, no hay que confundir la propuesta categorial de Hume con la idea de fantasy que se ha ido haciendo popular en el mundo a partir de la creación literaria anglosajona, es decir, con una derivación lúdica, repetitiva y encorsetada de las obras de Tolkien.

25 De este modo, entre sus obras encontramos el estudio Lo maravilloso medieval y sus categorías (2002), en que la autora contextualiza la concepción de esta modalidad literaria de acuerdo con una perspectiva propia, tras analizarla en correspondencia con la teoría previa y el pensamiento sobre la mentalidad medieval. Así, resulta muy adecuada la aportación crítica sobre aquellos autores que han minusvalorado lo maravilloso, siempre a la sombra de lo fantástico, de Castex a Todorov pasando por Caillois o Mabille (Morales, 2002: 5-6). Igualmente, cabe hacer referencia a sus artículos "Las fronteras de lo fantástico" (2000), en que destaca una reflexión sobre la esfera religiosa y lo maravilloso en sus diversas modalidades afines, y "Función y forma de lo maravilloso en la literatura caballeresca: De la canción de gesta al roman" (2006), por la habilidad de exposición de la materia y su dominio a la hora de ejemplificar sus opciones teóricas.

${ }^{26}$ En otro ámbito de análisis se sitúan trabajos sobre lo maravilloso de los cuentos infantiles, en que se pone énfasis en lo moralizante y sus demás aspectos maravillosos. En ellos aquello vinculado con la literalidad y sus categorías posee una presencia nimia. En el ámbito hispánico cabe mencionar el volumen Ideología y cientos de hadas (1985), del chileno Hugo Cerda, cuyo marxismo férreo constriñe las conclusiones a que llega el autor: "Por eso, esta literatura debe contener todas las premisas que contribuyan a hacer del niño un militante de la revolución, que al fin y al cabo determinará su propia liberación del yugo de la necesidad" (Cerda, 1985: 16).

${ }^{27}$ Morales (2007: 162) aclara rápidamente que: "Si bien es cierto que el miedo no es exclusivo de lo fantástico - la literatura de horror es una prueba de ello-, para muchos teóricos y críticos, sería el primer paso en su dirección". 
en obras en que dominaría alguno de los tipos de maravilloso que ella se ha encargado de estudiar. De esta manera, contradice Le Goff, quien fijó para muchas generaciones de lectores e historiadores de formación que es mínima la sorpresa provocada por lo maravilloso entre los personajes o el narrador (Morales, 2007: 158). En relación con la credulidad que se nos ha transmitido como actitud principal en los siglos medievales - concepción que entronca con la imagen de ignorancia y tinieblas del saber que se difundió desde el autodenominado Renacimiento-, la investigadora mexicana advierte que no por encontrarse en la Edad Media las instancias intratextuales se crean siempre lo que oyen, ya que muchas veces necesitan visionar esa maravilla para su convencimiento pleno (Morales, 2007: 166).

\subsection{LA POSICIÓN EXTRATEXTUAL DE DAVID ROAS}

Si bien desde la Península ibérica ha habido aportaciones destacables en el ámbito de la historia de lo fantástico en sus diferentes vertientes, han resultado más bien esporádicas $^{28}$. Con una magna excepción: A David Roas, profesor de la Universitat Autònoma de Barcelona, se le puede considerar, sin duda, el mayor especialista en lo fantástico del ámbito español. Es autor del único reader de referencia en esta lengua ${ }^{29}$ sobre la materia, Teorías de lo fantástico (2001), que además contiene una introducción y una bibliografía muy completas de las diferentes aproximaciones históricas a lo fantástico, presentadas desde un punto de rigurosamente académico. Esta actitud de alta divulgación combinada con un discurso fluido y la voluntad de crear un estado de opinión para poder debatir sobre puntos sensibles de la teoría de lo fantástico culminaría 10 años después con la publicación de Tras los límites de lo real: una definición de lo fantástico (2011), la cual — como el mismo título indica — pretende ser una aporta-

${ }^{28}$ Sobre la literatura española peninsular, cabe destacar un par de colecciones artículos que, a pesar de su tendencia dominante hacia el estudio de periodos breves o autores específicos, suponen magníficas aportaciones al campo de estudio. Se trata de las obras editadas - singularmente - por Jaume Pont, de la Universitat de Lleida, en Cataluña: Narrativa fantástica en el siglo XIX: España e Hispanoamérica (1997) y Brujas, demonios y fantasmas en la literatura fantástica hispánica (1999). En el mismo camino, Ana Casas analiza un periodo quebradizo y muy poco tratado: "El cuento fantástico durante la posguerra española: algunas calas a través de las revistas literarias de los años 50 y 60 ", de considerable interés por analizar con ahínco las relaciones entre el credo del realismo social en boga y las manifestaciones de lo fantástico en las publicaciones períodicas. Por otro lado, García Sánchez (1998) realiza un arriesgado ejercicio de abducción de señales iniciales de lo fantástico en el Siglo de Oro, argumentando que entonces se empieza a constituir una cultura racionalista orientada hacia los datos de la experiencia (García Sánchez, 1998: 88). En cambio, la brillante investigadora Neus Rotger (2007) resigue la teorización sobre lo fantástico como modalidad fundada sobre límites desestabilizados a la hora de negociar sentidos, hallando brechas en planteamientos de críticos como Italo Calvino.

${ }^{29}$ El volumen se incluye en la colección de antologías críticas por excelencia de la teoría de la literatura en español, "Lecturas", de la editorial madrileña Arco/Libros. 
ción personal al estudio de esta modalidad literaria ${ }^{30}$. Paralelamente, Roas ha llevado a cabo una labor sin par en la recopilación de materiales literarios relacionados con la literatura fantástica española en sus albores, desde mediados del s. XVIII hasta finales del s. XIX. En concreto, se trata de volúmenes que demuestran una sólida investigación de fondos archivísticos y que trabajan de manera especial la recepción de aquellos autores extranjeros que marcaron las pautas a seguir en la novedad de lo fantástico de ese entonces: Hoffmann en España. Recepción e influencias (2002), De la maravilla al horror: Los inicios de lo fantástico en la cultura española $(1750-1860)^{31}$ (2006) y La sombra del cuervo: Edgar Allan Poe y la literatura fantástica española del siglo $X I X(2011)^{32}$. Por otra parte, el estudioso catalán también ha contribuido notablemente a aplicar esa mirada de seriedad académica a la producción literaria en español, no sólo a través de los estudios dedicados al fantástico clásico, sino también a través de antologías de lo fantástico en la literatura española del s. XIX y del s. XX ${ }^{33}$. En este sentido, el prólogo a La realidad oculta: Cuentos fantásticos españoles del siglo XX (2008), redactado a cuatro manos junto con Ana Casas, constituye seguramente la

${ }^{30}$ Además, esta obra fue merecedora del IV Premio Málaga de ensayo 2011.

31 Como buen complemento a este volumen encontramos el trabajo de Miriam López Santos, de la Universidad de León, con el título La novela gótica en España (1788-1833) (2010), que resucita un género literaria cuasi fantasmagórico en las letras españolas, fijando su debida trascendencia y sus insospechadas repercusiones.

${ }^{32}$ A través de su tarea investigadora, Roas llega a conclusiones que resaltan el importante papel de los autores que ha estudiado en el desarrollo de lo fantástico decimonónico en la literatura castellana de la Península. Sobre Edgar A. Poe afirma: "Nadie fue ajeno a la obra del autor americano, cuya sombra se extendió de forma indeleble sobre la cultura española" (Roas, 2011a: 183). Y sobre E.T.A. Hoffmann, concluye: “[...] su papel fue esencial en la popularización y el consumo de lo fantástico en España, pues este género se convirtió en una verdadera moda a partir del momento en que Hoffmann empezó a ser leído y traducido en la década de 1830” (Roas, 2011a: 11)).

${ }^{33}$ Nos referimos a Cuentos fantástico del siglo XIX (España e Hispanoamérica) (2003) y La realidad oculta: Cuentos fantásticos españoles del siglo XX (2008), este último en colaboración con la profesora de la Universidad de Alcalá Ana Casas. En lo que se refiere a la recopilación de materiales literarios de calidad de lo fantástico español peninsular del siglo XIX, cabe destacar la colección Cuentos fantásticos en la España del Realismo (2006), de Juan Molina Porras, el cual —igual que Roaspone de manifiesto la existencia de una destacable corriente decimonónica interesada en lo irracional y lo sobrenatural como motores del texto artístico, frente al hegemónico grueso del Realismo canónico. El estudio de Molina Porras que presenta el volumen resulta un instrumento de síntesis muy apto para conocer el contexto de creación de dichos autores, algunos de los cuales ya eran difíciles de rastrear, como por ejemplo Luis Valera. Con todo, hay que indicar que la visión del antólogo se expande más allá de lo estrictamente fantástico —que él mismo reconoce poco productivo en el XX español—, con el objetivo de "[...] ofrecer a los lectores una visión completa y compleja de la literatura fantástica de las últimas décadas del siglo XIX” (Molina Porras, 2006: 19, 25). Incluye, así, cuentos maravillosos, de anticipación científica, grotescos y onírico-alucinatorios. Entre las diversas antologías que circulan, más o menos específicas y más o menos rigurosas en lo categorial, hay que destacar por contraposición a las dos mencionadas la Antología española de literatura fantástica (1992), a cargo de Alejo Martínez Martín, cuyos criterios de selección — pese a la calidad de la mayoría de textos— dejan bastante más estupefacto que las transgresiones preternaturales presentes en alguno de los textos. 
mejor síntesis aproximativa a la historia de lo fantástico peninsular en castellano de ese periodo. Finalmente, no podemos sino destacar que ha sido el principal impulsor del I Congreso Internacional sobre lo fantástico en narrativa, teatro, cine, televisión, cómic y videojuegos, que se celebró en Barcelona en noviembre de 2012 y que supuso uno de los mayores eventos de estas características — dada la amplitud de mirasdentro del hispanismo europeo ${ }^{34}$.

En la introducción a su antología de textos teóricos sobre lo fantástico, que significativamente se titula "La amenaza de lo fantástico", Roas no toma el camino de la equidistancia. Así, si bien presenta a Todorov como el autor de la "[...] obra fundacional en los estudios sobre el género fantástico [... ${ }^{\prime 3}$, nos advierte al mismo tiempo que se trata de uno de los críticos que se han dedicado a buscar una cualidad inmanente a los textos, habiendo argumentado previamente a lo largo de diversas páginas de texto "[...] la necesaria relación de lo fantástico con el contexto sociocultural: necesitamos contrastar el fenómeno sobrenatural con nuestra concepción de lo real para poder calificarlo de fantástico" (Roas, 2001: 14-15). El camino de la vinculación entre la modalidad narrativa que tratamos y la realidad extratextual está tomado $^{36}$. Se trata de una realidad vista, además, desde postulados constructivistas, es decir, como construcción sociocultural ${ }^{37}$, pero personificada en un lector real cuya participación activa es "[...] fundamental para la existencia de lo fantástico [...]" (Roas, 2001: 20). Esto nos lleva a una concreción histórica del hecho literario fantástico, ya que, al parecer del estudioso barcelonés, antes del siglo XVIII “[...] lo sobrenatural pertenecía, hablando en términos generales, al horizonte de expectativas del lector" (Roas, 2001: 21), afirmación que ya hemos visto como Morales intentaba matizar recurriendo al acercamiento a determinados textos medievales. ¿Hasta dónde llegan, pues, esos "términos generales" a los que se refiere Roas? ¿Se trata, como él mismo asevera, de una cuestión de verosimilitud de lo sobrenatural canalizada mediante el discurso religioso (Roas, 2001: 21)?

${ }^{34}$ En este caso, con todo, hay que mencionar el I Congreso Internacional de literatura fantástica y ciencia ficción, que se celebró en la Universidad Carlos III de Madrid en 2008. De su éxito de participación salieron publicadas unas impresionantes actas en formato electrónico, bajo el título Ensayos sobre ciencia ficción y literatura fantástica (2009), editadas por T. López Pellisa y F.Á. Moreno Serrano.

${ }^{35}$ La crítica a Todorov se complementa con un rechazo recurrente en otras críticas postodorvianas, incluso aquellas que se caracterizan por su perspectiva intratextual: "A mi entender, ésta es una definición muy vaga y, sobre todo, muy restrictiva de lo fantástico [...]" (Roas, 2001: 16).

${ }^{36}$ Resulta altamente significativa la contraposición del artículo de Roas (2004) en Odiseas de lo fantástico, titulado llamativamente "Contexto sociocultural y efecto fantástico: un binomio inseparable", con el de Morales (2004), que le precede y que — como se ha visto- expone unos planteamientos harto distantes.

37 “[...] Mi propia teoría de lo fantástico [...] concibe dicha categoría como un discurso en relación intertextual constante con ese otro discurso que es la realidad, entendida siempre como una construcción sociocultural" (Roas, 2011b: 9). 
Lo que no se pone en duda en ningún momento es la naturaleza histórica de una modalidad literaria que necesita del racionalismo y de effets de réel de fondo para convencer al lector extratextual de la verosimilitud de los hechos narrados, situación que permitirá al narrador del relato fantástico presentar el fenómeno sobrenatural del mismo como una "realidad análoga" al del contexto realista en que se ha sumido el lector (Roas, 2001: 25). En el crítico catalán, esta cuestión es tan crucial en el entramado de sus planteamientos que habla de "hiperrealismo" a la hora de definir las técnicas narrativas que se emplean en los relatos fantásticos (Roas, 2001: 26). Gracias al poderoso contraste entre el marco de realidad aumentada y un fenómeno inexplicable que viene a romper con la monotonía de lo real, se produce un efecto de miedo o inquietud en el lector ${ }^{38}$, el cual — como se ha dicho- se ve incrementado por el efecto de hacer análogamente verosímil el hecho sobrenatural, supuestamente de naturaleza sobrecogedora ${ }^{39}$. El tesón a la hora de postular el miedo como efecto fundacional de lo fantástico, que por ejemplo se constata en las alabanzas a los planteamientos teóricos de Lovecraft, proyecta al estudioso catalán hacia un psicologismo que tiene su base principal en las reflexiones de Freud (1986) acerca del concepto del Unheimliche en su renombrado artículo de 1919. En efecto, la amenaza que nace de las situaciones que el gran impulsor del psicoanálisis presenta en relación con la idea del desdoblamiento - en un amplio abanico de casuísticas - contrasta con la placidez que atribuye al campo de lo maravilloso, en que lo imaginario se concentra en mundos alternativos sin contacto amenazante con los sujetos reales. Se trata de la misma contraposición de mundos posibles que Roas ofrece en su introducción al reader y en otros de sus trabajos académicos, llevándole a atribuir a lo fantástico - en todas sus manifestaciones artísticas (literatura, cine, teatro, etc.) y no estrictamente artísticas (videojuegos) (Roas, 2011b: 10) - ese controvertido efecto que va de la inquietud al terror ${ }^{40}$.

Sin salir del tema de la amenaza inherente a esta modalidad literaria, llegamos a la literatura que se elabora en el paso de la modernidad en decadencia a la posmodernidad triunfante, periodo este último que contiene un gran número de ejemplos de

${ }^{38}$ Roas (2001: 32) declara repetidamente su entronque con otros teorizadores de lo fantástico que previamente ya habían estipulado la exigencia de una sensación extratextual de miedo o inquietud, como Caillois, Bellemin-Noël y Bessière por la parte francófona, y Lovecraft por la parte anglosajona.

39 El empleo y la significación psicológica de tales términos serán aclarados por Roas (v. 2011b: 81-84) en un trabajo posterior de la mano, entre otros, de Jean Delumeau, el cual señala que en psiquiatría el miedo (pavor, horror, etc.) lleva a lo conocido — un objeto determinado de temor al que se puede hacer frente - y la angustia (inquietud, ansiedad, etc,) lleva a lo desconocido, provocando una sensación global de inseguridad. Con todo, entre miedo y angustia Roas (2011b: 83) prefiere usar en sus trabajos el primero por comodidad y economía.

${ }^{40}$ Para una aproximación desde el mundo hispánico a la literatura meramente terrorífica, sea de naturaleza fantástica o no, v. Martínez de Mingo (2004). 
esta nueva variante de lo fantástico. Todorov lo eliminaba del cuenco del género que había aislado con precisión quirúrgica, afirmando que en el siglo XX el psicoanálisis debía sustituir a este tipo de narración, mientras que otro teorizador de lo fantástico, el argentino Jaime Alazraki, etiquetaba algo más tarde el fenómeno literario que iba de Kafka a Cortázar como lo neofantástico. En ambos casos, Roas presenta objeciones importantes (v. Roas, 2001: 34-42). De este modo, a su buen entender, lo fantástico no ha cambiado en esencia, por lo que no necesita ser trasplantado mediante un prefijo a un terreno en que, según Alazraki (2001: 277), ha desaparecido cualquier tipo de efecto de miedo en los lectores, sean implícitos o extratextuales ${ }^{41}$. Para el autor barcelonés, lo fantástico solo ha evolucionado lo suficiente para adaptarse a una nueva realidad, pero sin perder el efecto de siniestra amenaza sobrenatural, ya que, en el fondo, la visión de la realidad posmoderna como entidad indescifrable - construida por teóricos y ensayistas - es una entelequia que funciona perfectamente en el mundo intelectual de los avances científicos en física (a nivel cósmico y subatómico) y neurobiología, en la reflexión sobre la tecnología del ciberespacio o en el desarrollo radical de la filosofía constructivista (v. Roas, 2011b: 21-30), mientras que la mayoría de lectores reales, los extratextuales, continuamos en un marco de realidad basada en el principio de no contradicción, la lógica causal y el temor ante cualquier tipo de fenómeno sobrenatural que amenace nuestras expectativas de mundo. En este sentido, Roas considera que en lo fantástico continúan funcionando los mismos mecanismos de base, consistentes en introducir algo inexplicable y provocar así un cierto tipo de miedo: "[...] la irrupción de lo anormal en un mundo en apariencia normal, pero no para demostrar la evidencia de lo sobrenatural, sino para postular la posible anormalidad de la realidad, para revelar que nuestro mundo no funciona como creíamos" (Roas, 2006b: 114).

A partir de su reflexión sobre los efectos psicológicos de la lectura de textos fantásticos en todas sus variantes, Roas concibe un tipo de miedo que bautiza como "metafísico o intelectual" (Roas, 2006b: 108). El crítico catalán, que lo localiza tanto en lo fantástico decimonónico como en lo fantástico contemporáneo, asegura que " [...] se produce cuando nuestras convicciones sobre lo real dejan de funcionar, cuando [...] perdemos pie frente a un mundo que antes nos era familiar" (Roas, 2006b: 111112). La duda que debería surgir entre los conocedores de las características atribuidas a la literatura posmoderna se referiría a los efectos irónicos o paródicos presentes en

41 "Neofantásticos porque a pesar de pivotear alrededor de un elemento fantástico, estos relatos se diferencian de sus abuelos del siglo XIX por su visión, intención y su modus operandi. [...] Por su visión [...] lo neofantástico asume el mundo real como una máscara, como un tapujo que oculta una segunda realidad que es el verdadero destinatario de la narración neofantástica. [...] En lo que toca a la intención, el empeño del relato fantástico dirigido a provocar miedo en el lector, un terror durante el cual trastabillan sus supuestos lógicos, no se da en el cuento neofantástico" (Alazraki, 2001: 276-277). 
buena parte de ella, también en obras catalogadas por Roas en la casilla de lo fantástico moderno, puesto que la comicidad de ambas anularía la inquietud o el miedo que se reclama a nivel emocional. El investigador lo resuelve manteniendo que, en los relatos que podemos considerar fantásticos, lo cómico nunca se impone a lo fantástico, sino que este último sigue constituyendo el eje de la narración: "Así, la combinación de lo fantástico con la ironía y/o parodia potencia el efecto distorsionador del relato, sin que, por ello, los fenómenos narrados pierdan su condición de imposibles, puesto que tales recursos nunca se imponen al objetivo central de lo fantástico" (Roas, 2011b: 172-174). Además, lo humorístico contribuye a la necesaria regeneración de la modalidad literaria: "La ironía y la parodia son, por tanto, dos formas de dar nueva vida a recursos, temas y tópicos sobreexplotados tanto en la literatura como en el cine fantásticos" (Roas, 2011b: 175).

\section{A MODO DE CONCLUSIÓN}

En definitiva, no se puede negar que tanto Morales como Roas poseen el don de comunicar abiertamente sus tesis, cerciorados de su bondad, argumentándolas clara y sugestivamente, evitando la palabrería y las divagaciones vanas a que otros autores nos tienen acostumbrados. Ahora bien, mientras que Morales entronca con formulaciones de una teoría literaria que, rebosante de disquisiciones alternativas, pretendía afianzarse como disciplina autónoma con el máximo rigor metodológico, Roas entronca con un desapego desacomplejado a lo que Antoine Compagnon (1998) llamaría "le Démon de la théorie", aunque no renuncia en absoluto a plantear una aproximación argumentada a sus convicciones acerca de lo fantástico. Además, la aproximación intratextual que reina en los análisis de Morales tiende a limitar el campo de estudio a lo literario, que es justamente el terreno en que la autora desarrolla sus investigaciones, con honestidad y amplitud de miras. Sin embargo, Roas prefiere moverse en ámbitos más diversos y que van más allá incluso de lo textual (el cine) y de lo meramente ficcional (los videojuegos), en un reto que supone una intermedialidad altamente compleja y atractiva. Ambos abarcan posiciones que, cual puntas de iceberg, ocultan una seducción por lo sobrenatural y misterioso que ha logrado altas cotas de investigación académica en el ámbito del Hispanismo.

\section{AGRADECIMIENTOS}

El presente artículo se enmarca en el proyecto de investigación "El componente ideológico en la literatura fantástica", financiado por el Narodowe Centrum Nauki (Centro Nacional de la Ciencia) de Polonia en base a la decisión DEC-2011/01/B/ HS2/03615. 


\section{BIBLIOGRAFÍA}

AlazraKi, Jaime (2001): “¿Qué es lo neofantástico?”. In: David RoAs [ed.], Teorías de lo fantástico (Bibliotheca Philologica / Lecturas). Madrid: Arco/Libros, 265-282.

Altamiranda, Daniel (2000): "Campo designativo de la expresión «Literatura Fantástica»". Escritos: Revista del Centro de Ciencias del Lenguaje 21: 59-76.

AnTEBI, Susan (2007): "De otros ajolotes: el cuerpo escrito del anfibio fantástico". In: Ana María Morales \& José Miguel Sardĩ̃as [ed.], Rumbos de lo fantástico: Actualidad e historia (Referencias, 6). Palencia: Cálamo, 75-94.

Aragón, Francisco (2008): "Reseña”. Con Notas VI 11: 249-255.

ArÁn, Pampa Olga (1999): El fantástico literario: Aportes teóricos (Comunicación y Lenguajes). Madrid: Tauro.

- (2004): "La construcción teórica del fantástico literario: lecturas y relecturas". In: Ana María Morales \& José Miguel Sardiñas [ed.], Odiseas de lo fantástico. México: Coloquios Internacionales de Literatura Fantástica, 3-24.

AristòtIL [Aristóteles] (1998): Retòrica / Poètica (Universitària, 10), trad. de Joan Leita, ed. de Alberto Blecua. Edicions 62: Barcelona.

CAmpra, Rosalba (2001): "Lo fantástico: Una isotopía de la transgresión". In: David RoAs [ed.], Teorías de lo fantástico (Bibliotheca Philologica / Lecturas). Madrid: Arco/Libros, 153-191.

- (2008): Territorios de la ficción: Lo fantástico (Iluminaciones, 40). Sevilla: Renacimiento.

CASAS, Ana (2006): "El cuento fantástico durante la posguerra española: algunas calas a través de las revistas literarias de los años 50 y 60”. In: Marco Kunz, Ana María Morales \& José Miguel SARDIÑAS [ed.], Lo fantástico en el espejo: De aventuras, sueños y fantasmas en las literaturas de España. México: Oro de la Noche, 159-172.

CAstro, Andrea (2002): El encuentro imposible: La conformación del fantástico ambiguo en la narrativa breve argentina (1862-1910) (Romanica Gothoburgensia, XLIX). Göteborg: Acta Universitatis Gothoburgensis.

CERDA, Hugo (1985): Ideología y cuentos de hadas (Akal Bolsillo, 109). Torrejón de Ardoz: Akal.

Compagnon, Antoine (1998): Le Démon de la théorie: littérature et sens commun (Points / Essais, 454). París: Éditions du Seuil.

FABRE, Jean (1992): Le miroir de sorcière: Essai sur la littérature fantastique. París: José Corti.

Freud, Sigmunt (1986): "Das Unheimliche". In: James Strachey [ed.], Obras Completas, XVII: De la historia de una neurosis infantil (el "Hombre de los lobos") y otras obras (1917-1919), trad. de José Luis Etcheverry, 2a ed. Buenos Aires: Amorrortu, 215-251.

GARCÍA SÁnchez, Franklin (1998): „Orígenes de lo fantástico en la literatura hispánica”. In: Antón Risco, Ignacio Soldevila \& Arcadio López-Casanova [ed.], El relato fantástico: Historia y sistema (Biblioteca Filológica, 8). Salamanca: Colegio de España, 85-114.

HAHN, Oscar (1998): "Trayectoria del cuento fantástico hispanoamericano". In: Antón Risco, Ignacio Soldevila \& Arcadio López-Casanova [ed.], El relato fantástico: Historia y sistema (Biblioteca Filológica, 8). Salamanca: Colegio de España, 169-180.

Hume, Kathryn (1984): Fantasy and Mimesis: Responses to Reality in Western Literature. Londres - Nova York: Methuen.

JACKSON, Rosemary (1981): Fantasy: The Literature of Subversion (New Accents). Londres: Routledge.

JoRDAN, Mery Erdal (1998): La narrativa fantástica: Evolución del género y su relación con las concepciones del lenguaje. Frankfurt am Main \& Madrid: Vervuert \& Iberoamericana.

Llarena, Alicia (1997): Realismo Mágico y Lo Real Maravilloso: una cuestión de verosimilitud. Gaithersburg: Hispamérica \& Universidad de Las Palmas de Gran Canaria.

Martínez de Mingo, Luis (2004): Miedo y Literatura (Ensayo, 21). Madrid: Edaf. 
Martínez Martín, Alejo [ed.] (1999): Antología Española de Literatura Fantástica (El Club Diógenes / Autores Españoles, 10), $4^{\mathrm{a}}$ ed. Madrid: Valdemar.

Merino, José María (2009): "Lo fantástico y la literatura española". In: Teresa López Pellisa \& Fernando Ángel Moreno Serrano, Ensayos sobre ciencia ficción y literatura fantástica. Madrid: Asociación Cultural Xatafi \& Universidad Carlos III de Madrid, 55-64 [documento electrónico].

Molina Porras, Juan (2006): “Introducción”. In: Juan Molina Porras [ed.], Cuentos fantásticos en la España del Realismo (Letras Hispánicas, 590). Madrid: Cátedra, 9-54.

Morales, Ana María (2000a): "Teoría y práctica de lo fantástico. Modelos y rupturas". Escritos: Revista del Centro de Ciencias del Lenguaje 21: 23-36.

- (2000b): "Las fronteras de lo fantástico". Signos Literarios y Lingüísticos II.2: 47-61.

- (2002): Lo maravilloso medieval y sus categorías (Cuadernos de Trabajo, 43). Puebla: Departamento de Ciencias del Lenguaje.

- (2004): "Transgresiones y legalidades (Lo fantástico en el umbral)". In: Ana María Morales \& José Miguel SardiÑas [ed.], Odiseas de lo fantástico. México: Coloquios Internacionales de Literatura Fantástica, 25-37.

- (2006): "Función y forma de lo maravilloso en la literatura caballeresca: De la canción de gesta al roman". In: Marco Kunz, Ana María Morales \& José Miguel Sardiñas [ed.], Lo fantástico en el espejo: De aventuras, sueños y fantasmas en las literaturas de España. México: Oro de la Noche, 29-48.

- (2007): "Credibilidad, percepción y reacción: Los vaivenes de lo maravilloso a lo fantástico". In: Ana María Morales \& José Miguel Sardiñas [ed.], Rumbos de lo fantástico: Actualidad e historia (Referencias, 6). Palencia: Cálamo, 155-177.

- (2008): "De lo fantástico en México". In: Ana María Morales [ed.], México fantástico: Antología del relato fantástico mexicano. El primer siglo. México: Oro de la Noche \& CILF, vii-xlii.

Pereira, Maria Eugénia (2007): “Realismo mágico y surrealismo: ¿Es posible una demarcación?”. In: Ana María Morales \& José Miguel Sardĩ̃as [ed.], Rumbos de lo fantástico: Actualidad e historia (Referencias, 6). Palencia: Cálamo, 199-213.

Pont, Jaume [ed.] (1997): Narrativa fantástica en el siglo XIX: España e Hispanoamérica (Actas). Lérida: Milenio.

- (1999): Brujas, demonios y fantasmas en la literatura fantástica hispánica (Actas). Lérida: Publicacions de la Universitat de Lleida.

Prada Oropeza, Renato (2006): "El discurso fantástico contemporáneo: tensión semántica y efecto estético". Semiosis 3: 53-76.

Prieto, Julio (2007): “"Viajeras razones»: metafísica y literatura fantástica, o el extraño caso de Macedonio y Borges". In: Ana María Morales \& José Miguel Sardiñas [ed.], Rumbos de lo fantástico: Actualidad e historia (Referencias, 6). Palencia: Cálamo, 261-274.

RoAs, David (2001): "La amenaza de lo fantástico". In: David RoAs [ed.], Teorías de lo fantástico (Bibliotheca Philologica / Lecturas). Madrid: Arco/Libros, 7-44.

- (2004): "Contexto sociocultural y efecto fantástico: Un binomio inseparable". In: Ana María Morales \& José Miguel Sardiñas [ed.], Odiseas de lo fantástico. México: Coloquios Internacionales de Literatura Fantástica, 39-56.

- (2006a): De la maravilla al horror: Los inicios de lo fantástico en la cultura española (1750-1860) (Biblioteca de Escrituras Profanas, 4). Vilagarcía de Arousa: Mirabel.

- (2006b): "Hacia una teoría del miedo y lo fantástico". Semiosis 3: 95-116.

- (2011a): La sombra del cuervo: Edgar Allan Poe y la literatura fantástica española del siglo XIX (Ensayo, 24). Madrid: Devenir.

- (2011b): Tras los límites de lo real: una definición de lo fantástico (Voces / Ensayo, 161). Madrid: Páginas de Espuma. 
— [ed.] (2003): Cuentos fantásticos del siglo XIX (España e Hispanoamérica). Madrid: Marenostrum.

Roas, David; Casas, Ana (2008): "Prólogo". In: David Roas \& Ana CASAs [ed.], La realidad oculta: Cuentos fantásticos españoles del siglo XX (Reloj de Arena, 32). Palencia: Menoscuarto, 9-54.

RотGer, Neus (2007): "Fronteras rotas: una aproximación a la literatura fantástica". In: Ana María Morales \& José Miguel Sardiñas [ed.], Rumbos de lo fantástico: Actualidad e historia (Referencias, 6). Palencia: Cálamo, 233-244.

SARDIÑAS, José Miguel (2006): "El pensamiento teórico hispanoamericano sobre literatura fantástica. Breve recorrido". Semiosis 3: 77-93.

SARDIÑAS, José Miguel [ed.] (2007): Teorías hispanoamericanas de la literatura fantástica (Valoración Múltiple). La Habana: Fondo editorial Casa de las Américas \& Editorial Arte y Literatura.

Todorov, Tzvetan (1970): Introduction à la littérature fantastique (Points / Essais, 73). París: Éditions du Seuil. 